\title{
A REVIEW OF ABACA FIBER-REINFORCED POLYMER COMPOSITES: DIFFERENT MODES OF PREPARATION AND THEIR APPLICATIONS
}

\author{
BIN JEREMIAH D. BARBA ${ }^{1,2}$, JORDAN F. MADRID ${ }^{2}$ AND DAVID P. PENALOZA JR. ${ }^{*}$ \\ ${ }^{I}$ Chemistry Department, College of Science, De La Salle University, Manila 1004, Philippines. \\ ${ }^{2}$ Chemistry Research Section, Philippine Nuclear Research Institute, Department of Science and Technology, Quezon City 1101, Philippines.
}

\begin{abstract}
Fiber-reinforced polymer composites have received increased attention due to their environmental friendliness and sustainability, aside from at par - if not better property enhancement achieved through fiber reinforcement over mineral-based fillers. The purpose of this article is to provide a comprehensive review on the various methods of fiber-based polymer composites preparation as well as their applications, particularly focusing on abaca-reinforced hybrid materials. Among the natural fibers available in the market, abaca fiber has been a major contender in the development of natural fiber composites. It has a great potential to be a renewable fiber source for industrial and technological applications owing to its inherent high mechanical strength, durability, flexibility and long fiber length. Impacts of different treatment strategies of abaca-based composites preparation resulting in property enhancements over bare polymer counterparts and that of synthetic fibers are discussed. Being eco-friendly and naturally sustainable, abaca fiber-reinforced composites can also exhibit better strength without substantial weight gain - characteristics that have been exploited in various commercial and technological uses. How these enhanced properties of the resulting composites had led in a wide range of applications such as in the automobile and construction industries and other fields had been included as well.
\end{abstract}

Keywords: polymer composites, abaca, fiber reinforcement, surface modification.

\section{INTRODUCTION}

Polymers play a ubiquitous role in everyday life. They are lightweight and low density materials with tunable properties which make them key ingredients in commodity, engineering, structural and advanced applications. However, compared to their metal and ceramic counterparts, they have relatively poor mechanical properties. To address this, fillers are added as load-carrying elements to provide strength and rigidity to the polymeric matrix, for its overall reinforcement. ${ }^{1-4}$ The resulting material is referred to as polymer composites.

High strength fibers have been the primary materials used in polymer reinforcement, especially synthetic fibers such as glass, carbon and aramid. Fiber-reinforced composites have the distinct advantage of having better strength, stiffness and lifetime for a wide variety of applications in various sectors, most notably in the automotive industry. ${ }^{5-7}$ Their usefulness has prompted continued growth in their production and mass volume, and with this came the alarming problem of disposal and sustainability. Excellent properties notwithstanding, synthetic fiber-composites are typically non-biodegradable and often non-recyclable. This has become a pressing issue especially with increasing environmental awareness and global concerns in climate change mitigation. As such, there has been renewed interest in the use of natural fibers as eco-friendly alternatives to synthetic fibers.

Natural fibers are sourced mostly from plants, though there are some obtained from animals. Lignocellulosic or cellulose-based fibers are of particular interest, and these terms will be used interchangeably with natural fibers throughout the text. They are classified into (1) bast fibers (e.g. banana, flax, hemp, jute, kenaf, ramie); (2) leaf fibers (e.g. sisal, pineapple, abaca, piassava); (3) fruit fibers (e.g. coconut, oil palm, assai); (4) seed fibers (e.g. cotton, coir, kapok) and (5) stalk fibers (e.g. wood, bamboo, grass, barley straw, bagasse). Since the 1990s, there has been an upward trend in publications pertaining to natural fibers and natural fiber composites because of their apparent environmental advantages such as biodegradability, lowered dependence on non-renewable energy/material sources and reduced pollutant emissions. ${ }^{7,8}$ Life cycle assessment studies of natural fiber composites showed that unlike their glass fiber composites counterparts - their production has lower environmental impact; their use of higher fiber content for equivalent performance reduces polluting base polymer content; their lightweight property improves fuel efficiency and reduces emissions; and their end of life biodegradability results in recovered energy and carbon credits. ${ }^{7}$ In favor of going green, natural fibers are gradually replacing synthetic materials in conventional composites.
Historical and current applications of natural fiber reinforced composite materials

Cellulose-based fibers have been historically used on as reinforcement in clothing, storage vessels, tools and construction components as early as $1500 \mathrm{BC}$. Archeological examination of Egyptian structures revealed their use of grass and straw to reinforce clay found in bricks and potteries. ${ }^{9}$ Polymer reinforcement started at around 1908, when paper and cotton were mixed with thermoset plastics to produce sheets, tubes and pipes. ${ }^{8}$ While they gradually fell out of favor as more durable synthetic counterparts dominated the market, they have once again gained traction in the past two decades.

The automotive industry has favored natural fiber composites in furthering lower costs and reduced weights for consequent higher fuel efficiency while maintaining the stringent demand of automobile components in terms of acceptable mechanical properties, acoustic absorption, processing suitability and crash behavior. ${ }^{10-12}$ This is especially apparent in European countries, where the use of natural fibers is encouraged by government legislation in their "End-ofLife Vehicle Regulation". The East German car, Trabant, was the first production car built from natural fiber composite, equipped with a cotton reinforced polyester chassis. ${ }^{13}$ BMW has been using lignocellulosic fibers since the $1990 \mathrm{~s}$. They used flax and sisal in their interior door linings and paneling for enhanced strength and impact resistance, cotton for soundproofing and wood fiber in car seats. ${ }^{14}$ DaimlerChrysler is the leading European manufacturer to incorporate natural fiber composite in their Mercedes-Benz vehicles (Figure 1).

They used jute composites in door panels, flax for engine and transmission covers and made use of other fibers such as abaca, hemp, sisal and wool for underbody panels, pillar inners, head liner, rear cargo shelf, trunk components and thermal insulation, reducing overall weight by $34 \% .^{11,15}$ Kenaf and wheat straw have been used in door panels and storage bin of some Ford vehicles. ${ }^{5}$ Volvo made use of soya-based foam linings in the seats of their C70 and V70 models along with a cellulose-based cargo floor tray. In 2008, Mazda started making use of kenaf reinforced poly(lactic acid) (PLA) in their interior consoles and seat covers. ${ }^{16}$ In Asia, Toyota leads the natural fiber initiative, using corn, kenaf and bamboo for various interior components. Other leading automobile manufacturers such as Fiat, General Motors, Honda and Volkswagen, have also incorporated natural fiber composites in their products. 


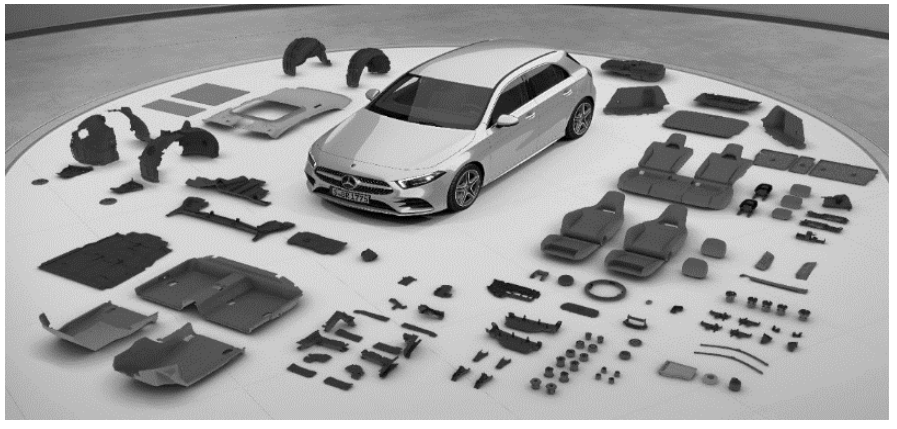

Figure 1. Model of the Mercedes-Benz A-class car and its component parts made of natural fiber composite (Adapted from Daimler AG, 2018) ${ }^{17}$.

Apart from applications in the car industry, natural fiber composites have also been used in building materials, aerospace, ships, textiles, packaging, electronics, sports goods, and other general commodities and advanced materials. ${ }^{12}$ Global market trend for natural fiber composites has reached US\$2.1 billion in 2010, with a $15 \%$ compound annual growth rate for the last two decades. ${ }^{18,19}$

\section{Pros and cons of natural fiber reinforcement}

Apart from the renewability and eco-friendliness, natural fibers have further advantages as polymer reinforcement materials. Compared to their synthetic counterparts, they are relatively cheaper than glass fibers. ${ }^{7,20,21}$ Furthermore, use of renewable agro-based resources presents opportunities for business development in countries short of non-renewable petroleum but have extensive agricultural vigor such as Southeast Asian countries. Plant sources are extensively cultivated in these regions and they generate abundant and useful fibrous waste.

Lignocellulosic fibers also possess favorable physical properties. They are low in density, usually only half of that of glass fibers $\left(\sim 2.6 \mathrm{~g} / \mathrm{cm}^{3}\right)$, thereby offering considerable reduction in weight. They are also typically stiffer than synthetic fibers with higher specific strength. They are also known to be less abrasive to processing equipment. ${ }^{8,22}$

Nevertheless, cellulose-based fibers are not without distinct disadvantages, which is why glass fibers still make up $95 \%$ of the composite industry. Natural fibers usually have heterogeneous structure with a large variation in their physical properties, often affected by cultivation practices and processing treatments. ${ }^{6}$ They are also highly hydrophilic. This makes them incompatible with typically hydrophobic matrices and enhances their moisture absorption which inadvertently affects their dimensional stability and susceptibility to microbial attack and rotting. ${ }^{23}$ They have low thermal stability which restricts their processing temperature greatly below the usual temperature used in thermoplastic or thermosetting polymer processing. And lastly, they are prone to degradation and aging with exposure to weathering elements. While these limitations provide roadblocks to their large-scale application, they also encourage research prospects into eliminating or minimizing these effects in order to better utilize their more promising properties.

\section{Abaca fibers as composite reinforcing materials}

Among the natural fibers available in the market, abaca fiber has been a contender in the development of natural fiber composites. ${ }^{24}$ The fiber is sourced from the abaca plant (Musa texitilis), also known as Manila hemp, which belongs to the Musaceae family, native to Asia. It morphologically resembles the banana plant with 12-30 stalks stemming from a central root system that gives it a shrubby appearance and a false trunk (Figure 2). Each of the stalks can grow up to 4-8 $\mathrm{m}$ and these are mechanically stripped, tuxied or decorticated to produce the abaca fiber. The obtained fiber is usually $1.5-3.5 \mathrm{~m}$ long and can be white, brown, red, black or purple in color. ${ }^{25}$

Abaca fibers are considered one of the strongest natural fibers in the market. It is currently used as components in paper, pulp, twines, ropes, textiles, fabric and fiber crafts, insulators, furnishings and household construction items. ${ }^{26}$ It also has a great potential to be a renewable fiber source for industrial applications owing to its high mechanical strength, durability, flexibility, buoyancy and long fiber length.
Ironically, it is considered a waste from the cultivation industry of abaca ${ }^{27}$ and costs only a fraction of that of synthetic fibers. The Philippines is the world's leading producer of abaca which supplies about $84 \%$ of the global demand, amounting to an annual average of 68,000 metric tons. ${ }^{28}$

The fiber is made up of around $60 \%$ cellulose, $21 \%$ hemicellulose, $12-16 \%$ lignin and $1 \%$ pectin. ${ }^{29}$ Its stiffness and strength are imparted by three important microstructural features: a high Runkel ratio, which denotes a high cell wall volume to lumen width (empty cavity within the fiber) proportion ${ }^{30}$; a high cellulose to hemicellulose and lignin content ${ }^{25}$; and a microfibril angle with orientation close to the fiber bundle ${ }^{31}$.
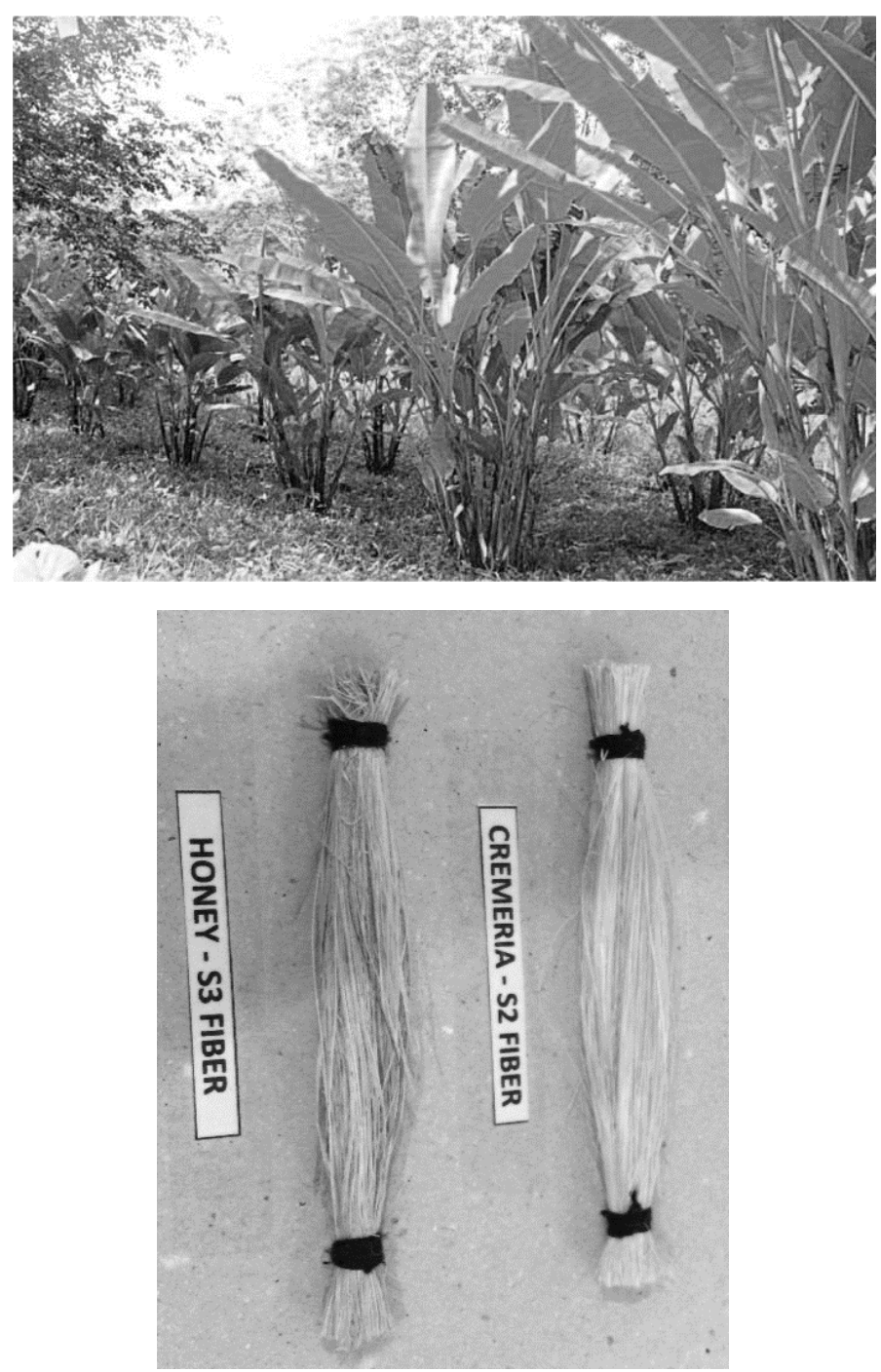

Figure 2. Abaca plants (top) and corresponding processed fibers (bottom) graded as $S 2$ and S3 (Adapted from PhilFIDA, 2009) ${ }^{28}$.

Abaca fiber can be classified into ten normal, four residual and one uncategorized quality grades as prescribed by the Philippine Fiber Industry Development Authority (PhilFIDA). In the interest of composite fabrication, the top grades Streaky Two (S2) and Streaky Three (S3) are commonly used, shown in Figure $3{ }^{32} \mathrm{~S} 2$, retrieved from the inner and middle tuxies of the leaf sheaths, is ivory white to very light brown in color with soft texture and normal to long length. S3, on the other hand, is usually shorter with dark red to dark brown color and is retrieved from the outer leaf sheaths. ${ }^{33}$

Abaca fiber, has $1.5 \mathrm{~g} / \mathrm{cm}^{3}$ density, $980 \mathrm{MPa}$ tensile strength and $41 \mathrm{GPa}$ elastic modulus. ${ }^{10}$ It is also known to be durable and resistant to seawater, which is why it is used as marine and naval cordage. Its specific flexural strength is comparable to glass fibers, ${ }^{34}$ and has a higher tensile strength than nylon and rayon. ${ }^{35}$ In recent years, its specific mechanical properties have made abaca fibers attractive materials for polymer reinforcement. 
Abaca reinforced composites: state of art. The potential of using abaca fibers as reinforcement fillers in composites was first realized in the works of Tobias. ${ }^{36,37}$ He used untreated short abaca fiber to reinforce thermoset resins and demonstrated in these works the importance of fiber loading and fiber length in optimizing tensile and impact strength. Meanwhile, Shibata and co-workers ${ }^{38}$ used abaca fibers with thermoplastic matrix. In their work, completely biodegradable composites were made from the melt mixing and injection molding of short abaca fibers and poly(3-hydroxybuterate-co-3hydroxyvarelate) (PHBV). At 20\% fiber loading, it was found to be comparable to glass fiber reinforced composite. Fiber pre-treatment with butyric anhydride and pyridine (benzoylation) showed improved flexural strength due to its increase interfacial adhesiveness with the polyester but was not effective in improving tensile modulus. The same group also investigated the reinforcement of poly( $\varepsilon$-caprolactone) (PCL). ${ }^{39}$ The use of acetic anhydride and butyric anhydride in pyridine as a pre-treatment led to a slight decrease in the tensile strength of the fiber itself but an increase in that of the PCL/abaca composite owing to better adhesion. The tensile strength of treated PCL/abaca was around $10 \mathrm{MPa}$ higher than PCL/glass fiber at the same fiber weight fraction. Again, there was no significant improvement in the tensile modulus.

In 2003, DaimlerChrysler started the abaca initiative in collaboration with Manila Cordage to develop abaca-reinforced composites for automobile components. By 2004, PP/abaca composites had been fully applied as underfloor paneling of the Mercedes-Benz A-Class vehicle. This was considered a first of its kind, as natural fiber- based composites were previously limited to interior parts. Their work recognized the suitable strength of abaca fiber for use even as exterior components which are subject to more stress and weathering..$^{40}$ Abaca fibers have been shown to give the best improvement on impact strength. ${ }^{41}$ This formulation has since been patented. ${ }^{42}$

Comparing PP/abaca to PP-composites of jute and flax showed that the abaca composites gave the best flexural strength and damping properties at maximum fiber load of $40 \% .{ }^{43}$ Meanwhile, an abaca fiber reinforced emulsion based biodegradable resin gave better tensile properties than composites reinforced by ramie, bamboo, banana, cotton and jute. ${ }^{24}$

Adhesion was significantly improved with the use of MAH-PP increasing tensile and flexural strength. ${ }^{44}$ Other treatments reported include the use of benzene diazonium salt, ${ }^{45}$ enzymes, ${ }^{46}$ and sodium hydroxide ${ }^{47}$ with noticeable improvement in mechanical properties as long as properly optimized. Abaca has also been used in conjunction with furan resin, ${ }^{48}$ epoxy resin, ${ }^{49}$ urea formaldehyde,$^{50}$ polylactic acid ${ }^{51}$ and high impact polystyrene ${ }^{52}$ with moderate success. Plasma treatment of abaca fabric enhanced its adhesion to unsaturated polyester and improved its wettability but exhibited notable low tensile strength even with supplementary mercerization and silylation. ${ }^{53}$

There have also been attempts at of creating hybrid composites made of two or more fiber components. Abaca-glass composites exhibited better ductility, elongation, flexural strength and modulus. ${ }^{20}$ Meanwhile, abaca-jute-glass displayed high impact strength. ${ }^{54}$

From reported literature, abaca fiber was shown to have formidable potential as a reinforcing agent in both thermosetting and thermoplastic polymers. However, there is still room for improvement, especially in the consistency in mechanical improvement of relevant mechanical properties such as flexural, tensile and impact strength as well as elastic modulus. Surface modification treatments have disadvantages that include low efficiency, loss of base integrity of the fibers and generation of chemical waste.

\section{Approaches via surface modification methods for fiber-reinforced composite preparation}

The variability of the properties of cellulose-based fibers depends on cultivation and processing conditions. However, with some regulation and rigorous quality control, a degree of uniformity may be attained for their use in composite fabrication. Natural fibers are typically classified into processed grades, with fiber diameter and length as important factors in improving quality by eliciting higher and more consistent strength values.

Another main area of improvement is the fiber's hydrophilicity and high moisture uptake - factors that significantly weaken interfacial interaction between the fiber and the polymer matrix. Adhesion of natural fibers to the polymeric network is essential to ensure even transfer of stress and improved mechanical performance. Even with its high specific strength, poor dispersion of the unmodified abaca fibers and weak interfacial interaction result from the incompatibility of the polar fibers with the nonpolar organic matrix. ${ }^{55,56}$ Lignocellulosic fibers are primarily composed of varying degrees of cellulose, hemicellulose, lignin and pectin. Their main functional groups are hydroxy groups which account for their hydrophilicity but may also serve as points vulnerable to modifications. ${ }^{57,58}$

Surface modification by physical treatments. Natural fibers can be modified by physical treatments such as stretching, ${ }^{59}$ calendaring, ${ }^{60}$ and heat treatment ${ }^{61}$ which can alter structural properties, typically introducing roughness for polymeric anchorage points. However, roughening often leads to deterioration of mechanical properties. ${ }^{62}$

Other treatments involve exposure to electric discharge, used successfully to improve mechanical properties of cellulose-reinforced poly(propylene) (PP). ${ }^{63}$ Corona treatment acts as a surface activator of oxidation to change the surface energy of the fiber. In wood fibers, this has been applied to increase the amount of less hygroscopic aldehyde groups ${ }^{64}$ while corona treatment of hemp led to significant increase in tensile strength. ${ }^{65}$ Meanwhile a similar method, cold plasma, can modify fiber surface by also changing surface energy, introducing crosslinks and inducing the formation of reactive functionalities. ${ }^{66}$ Quite unfortunately, electrical discharge-based processing encounters difficulty in the treatment of fibers, as its polarizing effect is dependent on energy level and exposure. ${ }^{67}$

Surface modification by chemical treatments. Since the main bottleneck of interfacial adhesion between the reinforcing fillers and the polymer matrix is the incompatibility of their surfaces, chemical modification of functional groups at the interface is the most convenient method to alleviate this problem. ${ }^{2,68}$ Since the polymer is usually at a higher content and has standardized properties, it is more practical to modify the filler component by making it less hydrophilic or by introducing new moieties to act as intermediary groups, such as coupling agents, to mediate interaction between two opposing polarities.

A common processing treatment for natural fibers is alkali treatment or mercerization. This treatment disrupts the composite architecture of the fiber, removing hemicellulose, lignin pectin, wax and oils to expose crystalline cellulose. It can reduce the fiber's ability to absorb moisture and even improve tensile properties. ${ }^{69}$ However, its use of high $\mathrm{pH}$ condition and surfactant content, generation of polluted wastewater and chemo-mechanical degradation make it a costly and unattractive process. Treatment can be easily overdone, converting the fiber into its weak amorphous form. ${ }^{70}$

Acetylation introduces an ester group to the fiber surface to make it less hydrophilic. The acetyl functionality will act like a hydrophobic coating to enhance matrix compatibility. Acetylation treatment was found to also remove non-crystalline constituents of flax, hemp and wood fibers, while altering surface topography and surface energy leading to an overall improvement in stress transfer efficiency and tensile strength..$^{22}$ This process is typically preceded by alkali treatment. Although at certain acetyl conditions, cellulose degradation and fiber cracking were also observed in flax fibers as a result of the catalysts used. ${ }^{34}$

One technique is through the use of coupling agents such as silanes. They have different functional groups at either end, for example capped with an amino moiety and with an epoxy or urethane end. The amino group can be used to attach to the hydroxyl group of the fiber and the other end can react readily with the polymer. This has successfully reduced hydrophilicity and enhanced the storage modulus of silylated polystyrene/kenaf composite. ${ }^{71}$

Another method of this type is maleated coupling which is widely used in conjunction with PP. In this case, it is the polymeric matrix which is modified instead of the fiber. Maleic anhydride can be used as an additive or copolymerized with PP (MAH-PP). The anhydride interfaces readily with the fiber hydroxyls and achieves better bonding and improved mechanical properties in the resulting composite. Maleic anhydride treatment can greatly augment wetting and dispersion of abaca, hemp and sisal in novolac composites and results in enhanced hardness, flexural modulus and impact strength. ${ }^{72}$

Other surface modification involves treatment with peroxides, potassium permanganate, sodium chlorite, benzoyl chloride, acrylonitrile and isocyanate 
stearic acid. ${ }^{56}$ Unfortunately, these treatments often involve toxic or hazardous chemicals which increase both production and disposal costs. They also do not always lead to the desired results. While compatibility is resolved, initial fiber strength decreases due to breakage of bond structures and disintegration of noncellulose components. ${ }^{73}$

Surface modification by radiation-induced grafting treatment. One of the most convenient and versatile techniques of surface modification is by graft copolymerization, or simply grafting, which can synthesize functional materials by attaching polymeric chains with advantageous properties to a trunk polymer with desirable bulk character but have usually inert or incompatible surfaces. This method can tailor the target substrate for specific chemistry and application by simply changing the polymer type, degree of polymerization, polydispersity and graft density (Figure 3). In the case of natural fibers for composite application, their physical and chemical properties may be changed at the surface or interface level, but their bulk properties, usually mechanical strength, are usually maintained. ${ }^{74}$

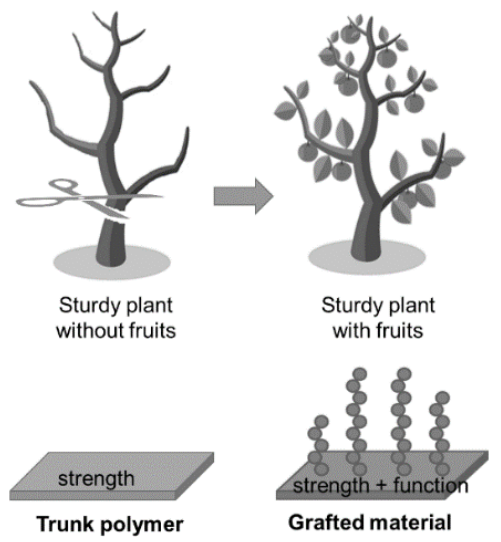

Figure 3. Attaching polymeric chains with advantageous properties to a trunk polymer with desirable bulk character through grafting.

There are currently two approaches to grafting cellulosic fibers (Figure 4). The "grafting to" approach attaches a pre-formed polymer on an activated surface. On the other hand, the "grafting from" approach grows the polymers on the substrate surface. The latter is more commonly used since better grafting density can be achieved as opposed to the steric crowding that limits the pre-formed chains in the case of the former. ${ }^{74}$

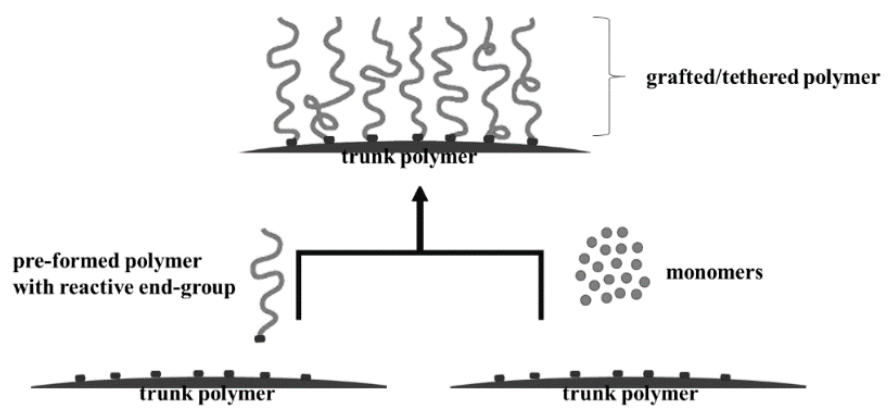

Grafting to

Grafting from

Figure 4. Synthesis of polymeric brushes by "grafting to" and "grafting from"

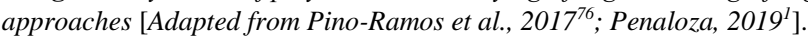

Grafting can be initiated by chemicals that can create reactive sites that will trigger the chain growth mechanism. These chemicals include peroxides, azobisisobutylnitrile, Fenton's reagent, persulfates, ceric ammonium nitrate or transition metal catalysts.

In the interest of reducing the use of toxic chemicals and organic waste, initiation by high energy radiation is a green alternative. Radiation-induced graft polymerization has the advantage of simple and facile preparation, absence of toxic initiators and chemicals, reactivity with a wide range of monomers while tolerating impurities, ability to combine two incompatible characters, and ability to work in mild conditions over a wide temperature range, allowing industries to impart desired functionalities.

Polymerization is initiated by the absorption of radiation from gamma rays or electron beam (e-beam). These sources of ionizing radiation differ in penetration depth and dose rate. They are applied accordingly in three different grafting modes. Gamma irradiation is typically used for simultaneous grafting, where both the monomer solution and trunk polymer are exposed to radiation. While the substrate is less prone to degradation in this scheme, there is formation of homopolymers. For pre-irradiation scheme, the trunk polymer is exposed to radiation to generate free radicals on its surface before immersion in the monomer solution. This method requires more resiliency from the trunk but reduces the monomer concentration significantly. E-beam is preferable for this scheme especially since its penetration depth is limited at low to moderate ebeam energies and therefore only surface modifications are introduced. Peroxidation schemes can either be simultaneous or pre-irradiation in the presence of air to form peroxides for prolonged retention of radical species followed by activation at moderate temperatures. ${ }^{77}$

Essential factors that affect radiation induced grafting and imparted properties include the nature of the substrate, nature of the monomer, concentration of components, absorbed dose and absorbed dose rate, grafting medium, temperature, and atmosphere. ${ }^{77}$

As previously mentioned, a wide range of monomers may be used in radiationinduced grafting, especially vinylic monomers. One of the most versatile monomers commonly used contains an acrylic and an epoxy group which serve as polymerization and functionalization precursors respectively. Examples of this type of monomers are glycidyl methacrylate (GMA) and 4hydroxybutylglycidyl ether (4-HBG). The functionalization is a simple ring opening reaction to introduce groups for desired properties like adsorption characteristic, conductivity, catalytic reactivity, hydrophilicity/hydrophobicity, thermal resistance, etc. ${ }^{78}$

The main disadvantage of radiation-induced grafting is that it follows a free radical polymerization scheme. As such, it has limitations in the control over molecular weight distribution, copolymer composition and macromolecular fine structure..$^{79}$ This can be resolved by employing controlled radical polymerization methodologies, e.g. use of chain transfer agents compatible with radiation initiation.

Some lignocellulosic fibers that have been successfully surface modified include kenaf with 4-chloro methylstyrene (CMS) ${ }^{80}$ and GMA $;{ }^{81}$ water hyacinth with GMA; ${ }^{82}$ jute with methyl methacrylate (MMA) ${ }^{83}$ and acrylonitrile; ${ }^{84}$ Hibiscus sabdariffa with $\mathrm{MMA}^{85}$; and sisal with styrene/ethyl acrylate. ${ }^{86}$ The grafted fibers exhibited improved mechanical properties and thermal resistance.

To date, there have been limited published works in the literature using abaca as the substrate in radiation-induced grafting, possibly due to the localization of raw material source and limited research centers in the country that employ radiation processing techniques on polymers. In the work of Madrid, Ueki, \& Seko (2013), abaca/polyester nonwoven fabric was grafted with GMA by preirradiation method. Degree of grafting was more than $100 \%$ using $50 \mathrm{kGy}$ at $5 \%$ GMA and $0.5 \%$ Tween 20 emulsion. The resulting grafted fabric was functionalized with ethylenediamine for metal adsorption applications. In another iteration, acrylic acid monomer was used, which achieved similar grafting yield at $40 \mathrm{kGy} .{ }^{87}$ Grafted and functionalized fabrics developed slight thermal resistance.

While high absorbed doses of ionizing radiation results in cellulose degradation by chain scission, abaca fibers have unique integrity such that its properties remain unchanged even after irradiation up to $100 \mathrm{kGy} .{ }^{87}$ This is a characteristic which cannot be observed from most other natural fibers. Moreover, grafting is typically done at low absorbed doses which do not cause significant fiber deterioration. ${ }^{89}$ With this, radiation-induced graft polymerization can be considered viable method of compatibilization for enhanced adhesion of abaca fibers in polymeric matrix and consequently improve mechanical properties. Moreover, as a green technique, it further contributes in lowering the carbon footprint of the generated natural fiber composite. 


\section{CONCLUSIONS}

Employing natural fibers, like abaca fibers, as reinforcing materials to prepare composites provides an alternative approach in preparing polymer-based composites with enhanced properties over their bare polymer counterparts and/or that of synthetic fiber-based materials. With effective fiber treatment and appropriate processing strategies, these abaca-reinforced composites not only help to reduce our dependence on non-renewable material sources but such appropriately modified natural fibers can also contribute in lowering the carbon footprint of the generated natural fiber composites. As had been discussed, various fiber treatment strategies can be aptly considered to address high hydrophilicity in natural fibers through modification methodologies resulting in reduced moisture absorption. When this is achieved, abaca fibers as reinforcing materials for composite materials can be made to demonstrate good fiber dispersion within the chosen matrix as well as encourage strong matrix-fiber interfacial interaction - both conditions have been shown to cause property enhancements in fiber-reinforced composites as established in various published works.

\section{ACKNOWLEDGMENT}

The Department of Science and Technology (DOST) is acknowledged for providing graduate scholarship to Bin Jeremiah D. Barba through the DOST Human Resource Development Program (DOST-HRDP).

\section{REFERENCES}

1. D.P. Penaloza, Philipp. J. Sci., 148, 827 (2019).

2. D. P. Penaloza, D.J. Sandberg, M.V. Giotto, T.A.P. Seery, Polym. Eng. Sci., 55, 2349 (2015)

3. A. Okada, A. Usuki, A, Macromol. Mater. Eng., 291, 1449 (2006)

4. E.P. Giannelis, Appl. Organomet. Chem., 12, 675 (1998)

5. K. Hill, B. Swiecki, J. Cregger, Center for Automotive (2012), https://www.cargroup.org/wp-content/uploads/2017/02/The-Bio_BasedMaterials-Automotive-Value-Chain.pdf

6. G. Se 'be, N.S. Cetin, C.A.S. Hill, M. Hughes, Appl Compos. Mater., 7, 341 (2000).

7. S.V. Joshi, L.T. Drzal, A.K. Mohanty, S. Arora, Compos. Part A Appl. Sci. Manuf., 35, 371 (2004)

8. O. Güven, S.N. Monteiro, E.A.B. Moura, J.W. Drelich, Polym. Rev., 56, 702 (2016).

9. T. Johnson, History of composites https://www.thoughtco.com/history-of-composites-820404

10. F. Ahmad, H.S. Choi, M.K. Park, Macromol. Mater. Eng., 300, 10 (2015).

11. J. Holbery, D. Houston, JOM, 58, 80 (2006).

12. L. Mohammed, M.N.M. Ansari, G. Pua, M. Jawaid, M.S. Islam, Int. J. Polym., 2015, 1 (2015).

13. A. Wagenführ, Lightweight Design worldwide, 10, 3 (2017).

14. J. Njuguna, P. Wambua, K. Pielichowski and K. Kayvantash, In Cellulose fibers: bio-and nano-polymer composites, edited by S. Kalia, B.S. Kaith, I. Kaur, Springer Nature, pp. 661-700 (2011), https://link.springer.com/chapter/10.1007/978-3-642-17370-7_23

15. L.J. Bingham, Automotive Industries 180, 83 (2000).

16. F.A. Mirza, A.M. Afsar, B.S. Kim, J.I. Song, Composites Research, 22, 41 (2009).

17. A.G. Daimler, New Mercedes-Benz A-class: Environmental Certificate for the A-class (2018), https://media.daimler.com/marsMediaSite/en/instance/ko/New-MercedesBenz-A-Class-Environmental-Certificate-for-the-AClass. $x$ html?oid $=40866452$

18. R. Fangueiro and S. Rana, Green composites for advanced technical applications. In 5th International Conference on Innovative Natural Fibre Composites for Industrial Applications. Rome, Italy (2015), https://www.researchgate.net/publication/285578124_Green_Composites_f or_Advanced_Technical_Applications

19. M. Ho, H. Wang, J.H. Lee, C. Ho, K. Lau, J. Leng, D. Hui, Compos. Part BEng., 43, 3549 (2012).

20. H. Venkatasubramanian, C. Chaithanyan, S. Raghuraman, and T. Panneerselvam, Int. J. of Adv. Res. in Sci. Eng. Tech., 1, 40 (2014).

21. G. Suresh, L.S. Jayakumari, G. Suresh, L.S.Jayakumari, Polímeros, 25, 49 (2015).

22. V. Tserki, N.E. Zafeiropoulos, F. Simon, and C. Panayiotou, Compos. Part A Appl. Sci. Manuf., 36, 1110 (2005).

23. A. Célino, S. Fréour, F. Jacquemin, P. Casari, Front. Chem., 1, 43 (2013).

24. S. Ochi, Compos. Part A Appl. Sci. Manuf., 37, 1879 (2006)
25. K. Vijayalakshmi, C.Y.K. Neeraja, A. Kavitha, J. Hayavadana, Transactions on Engineering and Sciences, 2, 16 (2014).

26. R.B. Armecin, F.G. Sinon and L.O. Moreno, In Biomass and Bioenergy, edited by K.R.Hakeem, M. Jawaid and U. Rashid, Springer Nature, pp. 108116 (2014), https://www.springer.com/gp/book/9783319075778

27. R. Punyamurthy, D. Sampathkumar, B. Bennehalli, C.V. Srinivasa, Chem. Sci. Trans., 2, 413 (2013)

28. PhilFIDA, Final technical report: Improvement of fiber extraction and identification of higher yielding varieties. Manila. (2009), http://www.philfida.da.gov.ph/images/Publications/abacasustainabilityman ual/ASM.pdf

29. R. Sun, J.M. Fang, A. Goodwin, J.M. Lawther, and A.J. Bolton, J. Agric. Food Chem., 46, 2817 (1998).

30. K. Liu, H. Takagi, Z. Yang, Compos. Part A Appl. Sci. Manuf., 45, 14 (2013).

31. B. Madsen, E.K. Gamstedt, Adv. Mater. Sci. Eng., 2013, 564346 (2013).

32. M.A. Paglicawan, B.A. Basilia, B.S. Kim, Composites Research, 26, 165 (2013).

33. F. Göltenboth, W. Mühlbauer, Abacá - cultivation, extraction and processing. In Industrial Applications of Natural Fibres (pp. 163-179) Chichester, UK: John Wiley \& Sons, Ltd. https://doi.org/10.1002/9780470660324.ch7

34. A.K. Bledzki, A.A. Mamun, M. Lucka-Gabor, V.S. Gutowski, Express Polym. Lett., 2, 413 (2008).

35. L.O. Moreno, Philipp. J. Crop Sci., 26, 21 (2001).

36. B.C. Tobias, Tomorrow's Materials: Today, 34, 211 (1989).

37. B.C. Tobias, In International SAMPE Symposium and Exhibition, 35 th, Anaheim, CA, pp. 970-978 (1990)

38. M. Shibata, K. Takachiyo, K. Ozawa, R. Yosomiya, H. Takeishi, J. Appl. Polym., 85, 129 (2002).

39. M. Shibata, R. Yosomiya, N. Ohta, A. Sakamoto, H. Takeishi, Polym Polym. Compos., 11, 359 (2003).

40. DaimlerChrysler. Annual Report. Stuttgart, Germany (2004), https://www.daimler.com/documents/investors/berichte/geschaeftsberichte/ daimlerchrysler/daimler-ir-annualreport-2004.pdf

41. A.K. Bledzki, P. Franciszczak, Z. Osman, M. Elbadawi, Indus. Crop. Prod., 70, 91 (2015).

42. R. Greiner, T. Schloeser, Rovings comprising Musaceae or banana plant fibers, used to reinforce composite automobile components, have limited contamination by processing aids, DE10349110B3 (2004). https://patents.google.com/patent/DE10349110B3/en

43. A.K. Bledzki, A. Mamun, O. Faruk, Express Polym. Lett., 1, 755 (2007).

44. J. Gironès, J.P. Lopez, F. Vilaseca, P.J. Herrera-Franco, P. Mutje, Compos. Sci. Technol., 71, 122 (2011).

45. M.R. Rahman, M.M. Huque, M.N. Islam, M. Hasan, Compos. Part A Appl. Sci. Manuf., 40, 511( 2009).

46. A.K. Bledzki, A.A. Mamun, A. Jaszkiewicz, K. Erdmann, Compos. Sci. Technol., 70, 854 (2010).

47. M. Cai, H. Takagi, A.N. Nakagaito, Y. Li, G.I.N. Waterhouse, Compos. Part A Appl. Sci. Manuf., 90, 589 (2016).

48. T. Tumolva, M. Kubouchi, S. Aoki, T. Sakai, In Proceedings of the 18th International Conference on Composites Materials, pp. 21-26 (2011) https://pdfs.semanticscholar.org/bc92/6868e47edd8f121bdfca500b737ee11 a0ac2.pdf

49. R.R. Niranjan, S. Junaid Kokan, R. Sathya Narayanan, S. Rajesh, V.M Manickavasagam, B.V. Ramnath, Adv. Mater. Res., 718-720, 63 (2013).

50. A.S. Suvarna, A. Katagi, J. Pasanna, S. Kumar, P.V. Badyankal, S.K. Vasudeva, Mat. Sci. Res. India, 12, 54 (2015).

51. A.K. Bledzki, A. Jaszkiewicz, Compos. Sci. Technol., 70, 1687 (2010).

52. E.H. Agung, S.M. Sapuan, M.M. Hamdan, H. Zaman, U. Mustofa, Int. J. Phys. Sci., 6, 2100 (2011).

53. M.A. Paglicawan, B.S. Kim, B.A. Basilia, C.S. Emolaga, D.D. Marasigan, P.E.C. Maglalang, Int. J. of Precis. Eng. and Manuf.-Green Tech., 1, 241 (2014).

54. B.V. Ramnath, S.J. Kokan, R.N. Raja, R. Sathyanarayanan, C. Elanchezhian, A.R. Prasad, V.M. Manickavasagam, Mater. Des., 51, 357 (2013).

55. T.A. Dankovich, Y.L. Hsieh, Cellulose, 14, 469 (2007).

56. X. Li, L.G. Tabil, S. Panigrahi, J. Polym. Environ., 15, 25 (2007).

57. V.S.D. Mesias, A.B.S. Agu, P.J.L. Benablo, C.H. Chen, D.P. Penaloza, J. Ecol. Eng., 20, 1 (2019).

58. B.S.C. Siy, J.A.X.C. Tan, K.P. Viron, N.J.B. Sajor, G.N.C. Santos and D.P. Penaloza, Cellulose Chem. Technol., 54, 365 (2020).

59. S. Haig Zeronian, H. Kawabata, K.W. Alger, Text. Res. J., 60, 179 (1990).

60. M.A. Semsarzadeh, Polym. Compos., 7, 23 (1986). 
61. P.K. Ray, A.C. Chakravarty, S.B. Bandyopadhaya, J. Appl. Polym. Sci., 20, 1765 (1976).

62. J.Y.Y. Heng, D.F. Pearse, F. Thielmann, T. Lampke and A. Bismarck, Compos. Interfaces, 14, 581 (2007).

63. M.N. Belgacem, P. Bataille, S. Sapieha, J. Appl. Polym. Sci., 53(4), 379 (1994).

64. I. Sakata, M. Morita, N. Tsuruta, K. Morita, J. Appl. Polym. Sci., 49, 1251 (1993).

65. M. Ragoubi, D. Bienaimé, S. Molina, B. George, A. Merlin, Ind Crop Prod, 31, 344 (2010).

66. Q. Wang, A. Ait-Kadi, S. Kaliaguine, J. Appl. Polym. Sci., 45, 1023 (1992).

67. J. Gassan, V.S. Gutowski, Compos. Sci. Technol., 60, 2857 (2000).

68. D.P. Penaloza, T.A.P. Seery, Mater. Res., 22, e201800192 (2019).

69. S.C.O. Ugbolue, Text. Prog., 20, 1 (1990).

70. M.M. Kabir, H. Wang, K.T. Lau, F. Cardona, Compos. Part B-Eng., 43, 2883 (2012).

71. Y. Xu, S. Kawata, K. Hosoi, T. Kawai, S. Kuroda, S. Express Polym. Lett., 3, 657 (2009).

72. S. Mishra, J.B. Naik, Y.P. Patil, Compos. Sci. Technol., 60, 1729 (2000).

73. S. Kalia, B.S. Kaith, I. Kaur, Polym. Eng. Sci., 49, 1253 (2009).

74. A. Hebeish, T. J. Guthrie, The chemistry and technology of cellulosic copolymers, Springer-Verlag Berlin Heidelberg (2012), https://www.springer.com/gp/book/9783540101642

75. D. Roy, M. Semsarilar, J.T. Guthrie, S. Perrier, Chem. Soc. Rev., 38, 2046 (2009).
76. V.H. Pino-Ramos, A. Ramos-Ballesteros, F. López-Saucedo, J.E. LópezBarriguete, G.H.C. Varca, E. Bucio, Top. Curr. Chem. (Z) 374, 63 (2016).

77. Y. Bhardwaj, M. Tamada, Y.C. Nho, M. Nasef, O. Guven, IAEA: Vienna, (2014), http://wwwnaweb.iaea.org/napc/iachem/working_materials/Graftingprotocol.pdf

78. M.M. Hassan, M.H. Wagner, Rev. Adhes. Adhes., 4, 1 (2016).

79. A. Rudin, P. Choi, A. Rudin, P. Choi, The Elements of Polymer Science \& Engineering, 341 (2013).

80. N.H. Mohamed, M. Tamada, Y. Ueki, N. Seko. Radiat. Phys. Chem., 82, 63 (2013).

81. J. Sharif, S.F. Mohamad, N.A.F. Othman, N.A. Bakaruddin, H.N. Osman, O. Güven, Radiat. Phys. Chem., 91, 125 (2013).

82. J.F. Madrid, G.M. Nuesca, L.V. Abad, Radiat. Phys. Chem., 85, 182 (2013).

83. F. Khan, Macromol. Biosci., 5, 78 (2005).

84. A.K. Mohanty, S. Patnaik, B.C. Singh, M. Misra, J. Appl. Polym. Sci., 37, 1171 (1989).

85. V.K. Thakur, A.S. Singha, B.N. Misra, J. Appl. Polym. Sci.,122, 532 (2011).

86. A.M. El-Naggar, M.B. El-Hosamy, A.H. Zahran, M.H. Zondy, Am. Dyestuff Rep, 81, 40 (1992).

87. J.F. Madrid, Y. Ueki, N. Seko, Radiat. Phys. Chem., 90, 104 (2013).

88. J.F. Madrid, P.J.E. Cabalar, L.V.Abad, J. Nat. Fibers, 15, 625 (2018).

89. W. Machnowski, B. Gutarowska, J. Perkowski, H. Wrzosek. Text. Res. J., 83,44 (2013). 